\title{
IN VITRO EVALUATION OF ACUTE CYTOTOXICITY OF HUMAN CHEMICALLY TREATED ALLOGRAFTS
}

\author{
D. Dufrane ${ }^{1 *}$, O. Cornu ${ }^{1}$, T. Verraes ${ }^{2}$, N. Schecroun ${ }^{1}$, X. Banse ${ }^{1}$, Y.J. Schneider ${ }^{2}$ and Ch. Delloye ${ }^{1}$ \\ ${ }^{1}$ Orthopaedics Research Laboratory, ${ }^{2}$ Cell Biochemical Laboratory, \\ Université Catholique de Louvain, Bruxelles, Belgium
}

\begin{abstract}
In order to minimize the risk of contamination associated with tissue transplantation, tissue banks commonly chemically treat the tissues whenever possible. As viral inactivation uses agents lethal to microorganisms, it is imperative to assure that chemically inactivated tissue remains biocompatible. In vitro assays can be an effective means to assess the acute cytotoxicity of chemically treated human allografts. We have used different types of cells cultured in the presence of treated tissue extract. A standard cell line, a human fibroblast (WI38), which was the same for all the samples, was chosen. In addition, as the banked tissues (bone and fascia lata) were prepared to be used in bone or as a dura mater substitute, two other cell types were also used: an osteoblastic cell line (SaOS-2) and a neuronal cell line (Neuro 2A). Cytotoxic assessment was performed by qualitative evaluation of cell morphology based on confluence, granulation, vacuolization and swelling analysis. In addition, quantitative methods based on the use of neutral red (NR) and 3- (4,5-dimethylthiazol2-yl)-2,5 diphenyl tetrazolium bromide (MTT) were assayed. Qualitative and quantitative evaluation of fascia lata and bone extracts did not show deleterious effects on cell cultures. These results show that in vitro methods can be appropriate to select a non-toxic procedure before it is used in the human body and that several strong chemical treatments can result in a tissue suitable for human implantation.
\end{abstract}

Key Words: Allografts, virus inactivation, biocompatibility, cytotoxicity, in vitro studies.

*Address for correspondence:

D. Dufrane

Orthopaedics Research Laboratory

Université Catholique de Louvain

Avenue Mounier 53, B-1200 Bruxelles, Belgium.

Telephone number: $+32-2-7645388$

FAX number: +32-2-7645371

E-mail: denis.dufrane@clin.ucl.ac.be

\section{Introduction}

Human tissue transplantation remains associated with a potential although very low risk of virus transmission [e.g., human immunodeficiency virus (HIV), or hepatitis] through orthopaedic allografts (Buck et al., 1989; Campbell et al., 1994; Eggen and Nordbo, 1992). However, Lelie et al. (1996), estimated that the risk was ten times higher in the case of organ or tissue transplantation when compared to blood transfusion. Various inactivation procedures have been advocated to reduce this risk (Delloye, 1994; Feinstone et al., 1983; Spire et al., 1984, 1985). Viral inactivation can be only obtained by serial step processing, using physical and chemical treatment such as supercritical $\mathrm{CO}_{2}$ (Fagès et al., 1994), solvent detergent (Feinstone et al., 1983; Spire et al., 1984), ethylene oxide (Kearney et al., 1993), freeze-drying (Conrad et al., 1995) or gamma irradiation (Campbell et al., 1994; Conway et al., 1991; Fideler et al., 1994; Forsell, 1993; Hernigou et al., 1993; Loty et al., 1990; Spire et al., 1985). However, such processing of the tissue can be restricted either by the potential toxicity for the recipient cells or by induced alterations of the original mechanical properties of the tissue (Zhang et al., 1997). The first aspect of tissue processing will be addressed here.

Inactivation procedures will not replace the microbiological screening of the donor but must be considered as an additional safety measure. In the past, one of the models for compatibility evaluation was animal implantation. Nowadays, the attempt to restrict in vivo experimentation has heightened the interest in using in vitro cell systems to appraise the potential cytotoxicity of allografts. Assessment of cell morphology is a reliable method in the hands of a trained morphologist (Srivastava et al., 1990). For morphological analysis, two different types of cells have been used: a standard cell line which is the same for all samples and a specific cell line the choice of which depends upon the potential site of use. However, in order to improve reproducibility and facilitate standardization, quantitative methods for acute cytotoxicity study were indicated (Kirkpatrick et al., 1997a,b).

Quantitative methods for in vitro cytotoxicity have been described and recommended in the literature, although the methods presently available cannot be easily automated (Johnson et al., 1985; Ulreich and Chvapil, 1981). A range of assays based on different aspects of cellular activity can be applied for the assessment of biocompatibility. In the 
present study, the 3-(4,5-dimethylthiazol-2-yl)-2,5diphenyltetrazolium bromide (MTT) and neutral red (NR) assays for quantitative evaluation which have been adapted for human inactivated allografts are presented (Borenfreund et al., 1988; Clifford and Downes, 1996; Dekker et al., 1994, Johnson et al., 1985; Mosmann, 1983; Verhulst et al., 1998).

The first group of assays measures the ability of viable cells to reduce a water-soluble yellow dye, MTT, to a water-insoluble purple formazan product (Clifford and Downes, 1996). This is converted by intracellular dehydrogenase to colored formazans (Macnair et al., 1997; Marshall et al., 1995). A second group of assays monitors cell membrane integrity, and is based on the spectro-photometric determination of NR (3-amino-2-methylphenazine hydrochloride) taken up by viable cells and stored in their lysosomes (Lasarow et al., 1992). The cytotoxicity testing of such allografts is vital to ensure that they do not present a risk to the patient and, therefore, will not elicit an acute toxicity response. The present study aimed at demonstrating that a strong chemical treatment could be associated with a low cytotoxicity outcome.

\section{Materials and Methods}

\section{Reagents and materials}

L-Glutamine $(200 \mathrm{mM})$ was from Life Technologies (Merelbeke, Belgium) and fetal bovine serum (FBS), Dulbecco's Modified Eagle's Medium (DMEM), Ham'S F-12 medium, and trypsin were supplied by Bio-Whittaker (Verviers, Belgium). Phosphate buffered saline solution (PBS), MTT, Coomassie blue, Bouin solution and Neutral Red were from Sigma-Aldrich Chemicals (Bornem, Belgium). Culture plates were supplied by Falcon-Becton Dickinson (Franklin Lakes, NJ).

\section{Human tissue allografts}

Fascia lata and bone from selected donors in our hospital were procured, cut in small pieces $\left(1 \mathrm{~cm}^{2}\right.$ for fascia lata and $1 \mathrm{~cm}^{3}$ for bone) and washed by pulse lavage. Next, chemical treatment with solvent detergent destroyed the cells of the allografts by protein coagulation, nuclear acid precipitation and cell membrane degradation. This treatment could also inactivate the viruses such as Hepatitis B and HIV and diminish the bacterial activity (Feinstone et al., 1983; Spire et al., 1984). As prion inactivation should become a priority for allografts, different methods recommended by World Health Organization (1992), as sodium hydroxide $(\mathrm{NaOH})$, sodium hypochlorite or autoclaving were applied to fascia lata and bone allografts trying to restrict the risk of Creutzfeldt-Jakob agent transmission (Brown et al., 1982, 1984; Dormont, 1996). Indeed, the prion protein has demonstrated a resistance to inactivation by gamma irradiation (Brown et al., 1982; Dormont, 1996). Allografts were further freeze dried for three consecutive days (working vacuum $1.10^{-6} \mathrm{~mm} \mathrm{Hg}$, shelf temperature $30^{\circ} \mathrm{C}$ and condenser temperature $-196^{\circ} \mathrm{C}$ ). The final residual moisture, as previously measured with other samples (by gravimetric analysis at $100^{\circ} \mathrm{C}$ ) for the same freeze dryer, was less than $1 \%$ of the final dry weight. So far, no case of virus transmission has been reported (Conrad et al., 1995). The sterilization was realized by gamma irra- diation at $25 \mathrm{kGy}$ which has been shown to be able to inactivate at least partially the HIV (Campbell and Oakeshott, 1995; Conway et al., 1991; Fideler et al., 1994; Forsell, 1993; Hernigou et al., 1993; Loty et al., 1990; Spire et al., 1985) and Hepatitis C virus (Conrad et al., 1995).

Different allografts were tested: Fascia lata Fresh (FF), Fascia lata Treated (FT), Bone Fresh (BF) and Bone Treated (BT).

\section{Established cell lines}

Human fetal lung cells (ATCC, American Type Culture Collection, Rockville, MD) (WI38, ATCC: $\mathrm{CCl} 75$ ) served as standard cell line. As fascia lata was prepared for being a dura mater substitute, Mouse Albino neuroblastoma cells (Neuro 2A, ATCC: CCL131) were used to monitor the neurotoxicity. The osteosarcoma cell line (SaOS-2, ATCC: HTB-85) was used to evaluate the bone toxicity.

\section{Material extract}

Under sterile conditions, the fragments of tendons and bone were immersed in the culture medium for $72 \mathrm{~h}$ at $37^{\circ} \mathrm{C}$ without agitation. According to ISO 10993-5, the ratio between the fascia lata area $\left(\mathrm{cm}^{2}\right)$ and the medium volume (ml) was 0.5 . For bone, the ratio was determined with the weight of the sample, $0.1 \mathrm{~g} / \mathrm{ml}$. The negative control, polyethylene terephtalate (PET), material which did not generate a cytotoxic response, was processed following the same extraction conditions (ISO 10993-5). Phenol solution $(10 \mathrm{mg} / \mathrm{ml})$ was used as positive control which when tested, generated a cytotoxic response. At the end of the incubation period, fragments of bone, fascia lata and PET were removed and the so-called extracts were ready to be tested.

\section{Cell culture}

Cells (WI38, SaOS-2, Neuro 2A) were maintained at $37^{\circ} \mathrm{C}$ in a humidified atmosphere of $5 \% \mathrm{CO}_{2}$ and $95 \%$ air. In order to prepare test wells, cells were detached from the culture flasks using a trypsin solution $(0.25 \%)$ and resuspended as a single cell suspension in the culture medium (DMEM+FBS+Ham'S F-12+ glutamine) at a concentration of $2 \times 10^{5}$ viable cells/ml (Trypan Blue exclusion test). Cells were seeded into the 96 inner-wells of microtiter plates for quantitative evaluation and into the wells of 12 well clusters for qualitative evaluation, at a density of $1 \times 10^{4}$ cells $/ \mathrm{cm}^{2}$ (i.e., microtiter plates, $1 \times 10^{4}$ cells/wells; 12-well clusters: 15-20x10 cells/wells). After an overnight incubation, a confluent monolayer of cells was formed in these wells.

\section{Qualitative evaluation}

Standard cells, WI38 as well as specific cells (SaOS-2 and Neuro 2A), were plated in 12-well plates and grown until confluence. The medium was removed, replaced by the allograft or PET extracts or by phenol solution. After time intervals of 24, 48 and 72 hours of incubation with extract, cells were examined microscopically by two different observers (phase contrast microscopy: optical microscope from Leitz, Wetzlar, Germany). Then, the preparation was fixed and stained with Coomassie Blue to preserve it and to allow to take a micrograph of the cells (Wild MPS12 photo systems attached to the optical microscope). This qualitative evaluation was carried out on confluence, swelling, vacuolization and morphological changes accord- 

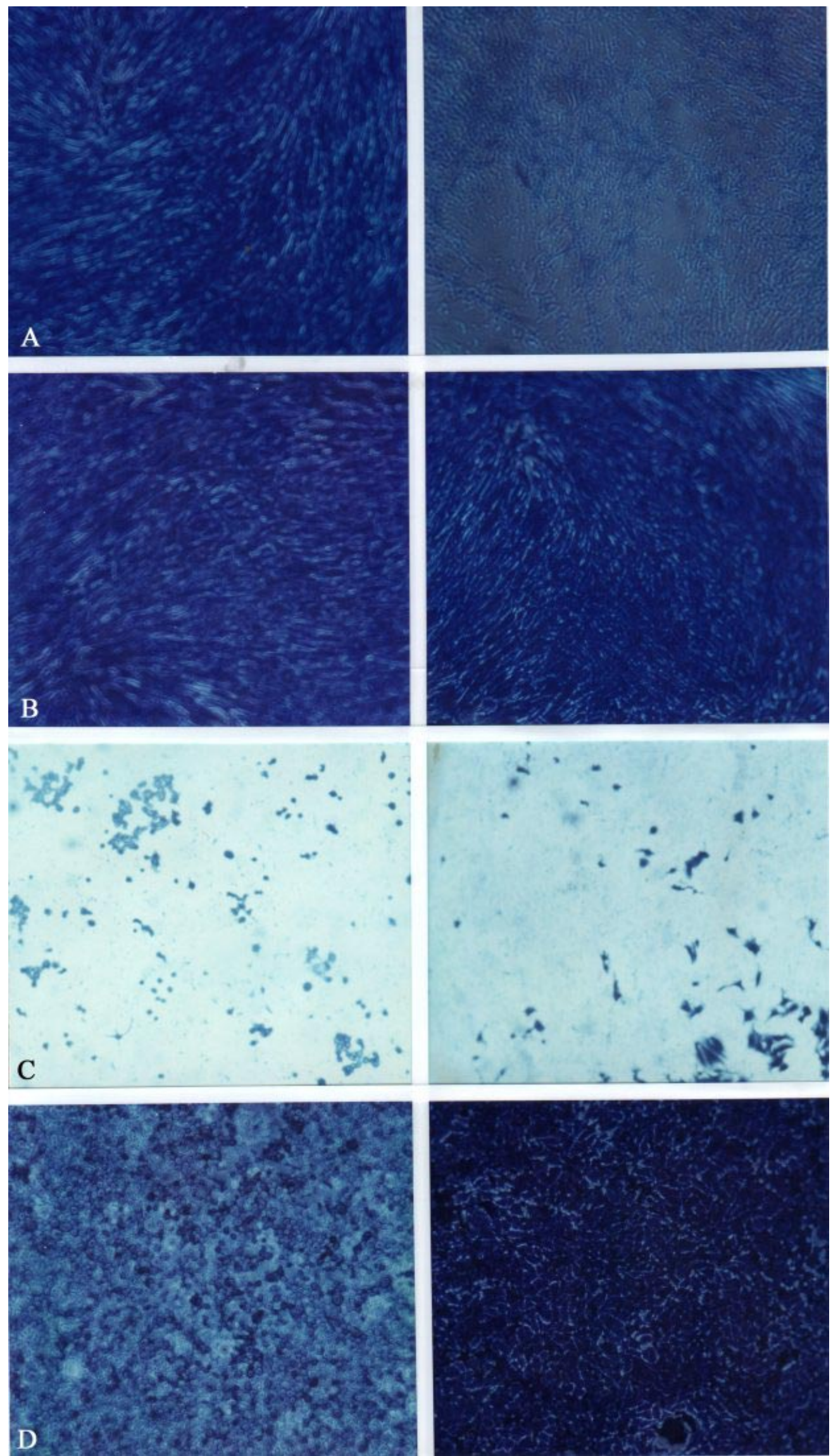

Figure 1. Photomicrographs of cell culture exposed to different extract vehicles. (A) WI38 with negative (left) and positive (right) control. Note the severe cytopathic effect with the positive control. (B) Culture of fibroblasts (WI38) with fascia lata (left) and bone allografts (right) extracts at 24 hours. (C) Culture of Neuro 2A (left) and SaOS-2 (right) exposed to the toxic control. (D) Culture of specific cell lines with fascia lata (Neuro 2A, left) and bone allograft extracts $(\mathrm{SaOS}-2$, right). Note the absence of deleterious cell reaction. Bar $=40 \mu \mathrm{m}$. 

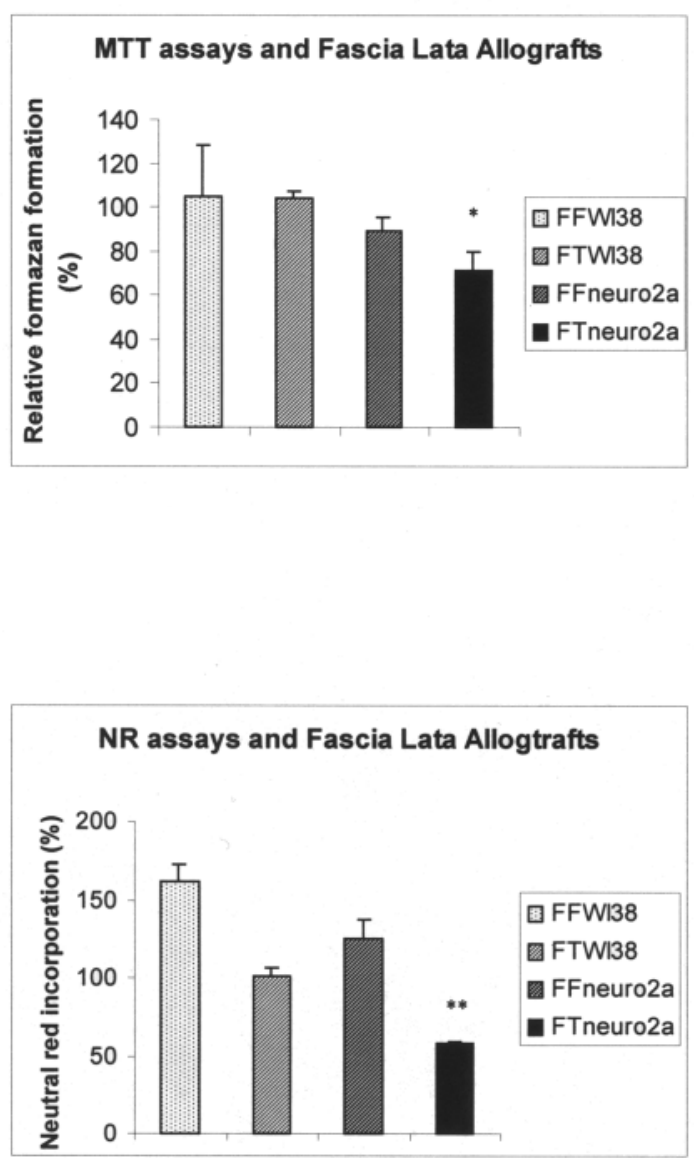

Figure 2. Relative MTT formazan formation by WI38 and Neuro 2A cells after incubation with fresh and chemically treated fascia lata extracts at 24 hours. Data obtained following incubation of cells with different extracts are expressed for MTT assay as percentages of the values obtained from cells incubated with the negative control and are the means $\pm \operatorname{SEM}(\mathrm{n}=4)(*=\mathrm{p}<0.05)$. ing to ISO 10993-5. These qualitative parameters were reported in the test report, either descriptively (no, slight, moderate or severe changes) or numerically $(0,1,2,3)$.

\section{Quantitative evaluation}

WI38 cells from the 10th passage were plated in 96well plates and grown until confluence during 24 hours. Then, the medium was removed and replaced by the allograft and negative control extract or phenol solution. Cells were incubated for $24 \mathrm{~h}$ at $37^{\circ} \mathrm{C}$. At the end of the extract incubation period, two different colorimetric tests were performed: one to evaluate cell viability (NR assay) and the other one to evaluate the cell metabolic activity (MTT assay). For the NR assay, cell layers were rinsed in PBS and then NR was added [100 $\mu 1$ per well of a $0.4 \%(\mathrm{w} / \mathrm{v})$ NR solution in distilled water, then diluted 1: 80 in culture medium]. After $3 \mathrm{~h}$ at $37^{\circ} \mathrm{C}$, the NR solution was removed and the dye extraction was performed by adding $100 \mu \mathrm{l}$ per well of a $1 \%$ acetic acid in $50 \%(\mathrm{v} / \mathrm{v})$ ethanol solution. The plates were agitated and finally the absorbance was measured at $540 \mathrm{~nm}$ using a microtiter plate spectrophotometer (Multiskan MCC/340 P Version 2.20, Titertek MK II; Labsystems, Brussels, Belgium). For the MTT assay, cell layers were rinsed as for the NR assay and then the MTT was added ( $125 \mu \mathrm{l}$ per well of a $5 \mathrm{mg} / \mathrm{ml}$ MTT solution in PBS). After 3 hours of incubation at $37^{\circ} \mathrm{C}$, the MTT solution was removed and the insoluble formazans crystals were dissolved in $100 \mu \mathrm{l}$ dimethylsulfoxide (DMSO). Finally the absorbance was measured as above. For both tests, the optical density was directly proportional to the viability and the metabolic activity of cell populations and inversely proportional to the acute cytotoxicity of the extract.

\section{Statistical analysis}

Mean values \pm standard error of the mean (SEM) of absorbances obtained from cells incubated in the presence of the extracts, either from controls or material extracts, were calculated. Results were expressed as the percentage of the corresponding negative control con-ducted in the same experiment. The unpaired Student's t-test was used for statistical analysis. A p-value $<0.05$ was considered statistically significant. The statistical tests were carried out using Systat version 8.0 (SPSS Inc., 1998).

\section{Results}

\section{Qualitative evaluation}

Incubation of standard (WI38) and specific (Neuro 2A and $\mathrm{SaOS}-2$ ) cell lines with extract of negative control and the extracts of chemically inactivated human allografts at intervals of 24, 48 and 72 hours did not influence the morphology of the cells. An intact monolayer of normally spread cells could be observed with only minor changes of confluence, vacuolization, granulation and morphological parameters. Morphological examination of cells which had been incubated with undiluted extract of the positive control clearly revealed a cytotoxic effect. In fact, incubation with the positive control resulted in a deterioration of the monolayer and loosening of the cells. The cells had lost their normal flat morphology and had become spherical. 

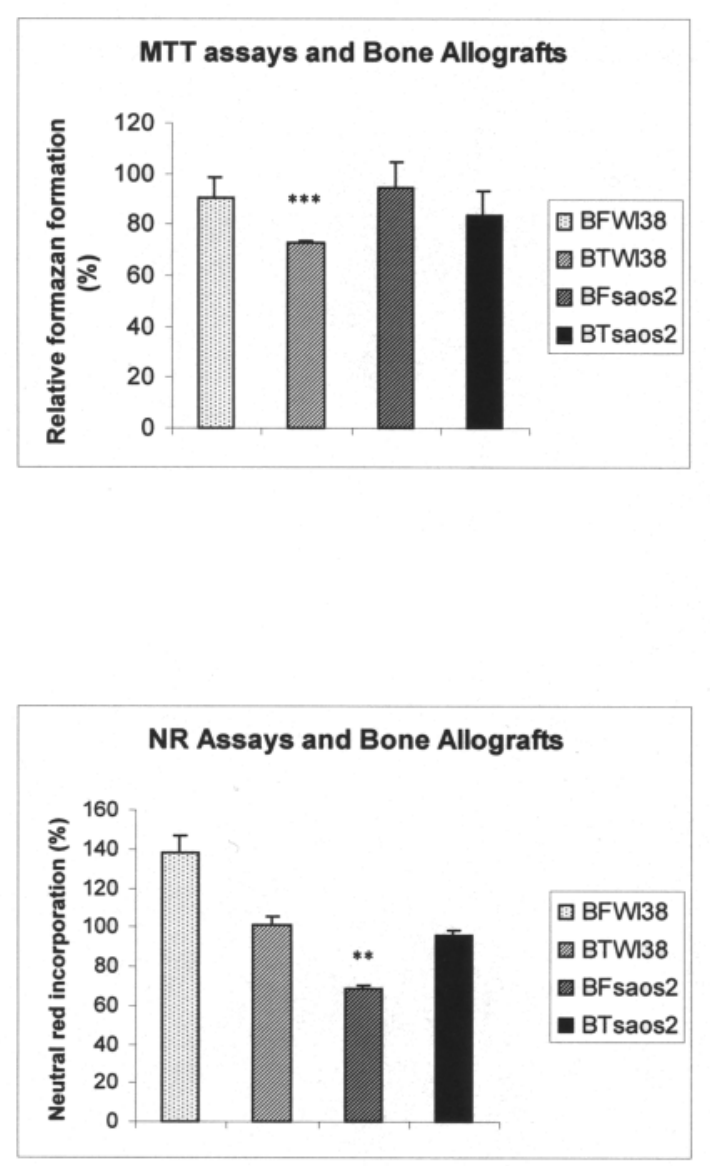

Figure 4. Relative MTT formazan formation by WI38 and SaOS-2 cells after incubation with fresh and chemically treated bone extracts at 24 hours. Data obtained following incubation of cells with different extracts are expressed for MTT assay as percentages of the values obtained from cells incubated with the negative control and are the means $\pm \operatorname{SEM}(\mathrm{n}=4)(* * *=\mathrm{p}<0.001)$.

Figure 5. The NR intra-lysosomal incorporation by WI38 and SaOS 2 cells after incubation with fresh and chemically treated bone ex-tracts at 24 hours. Data obtained following incubation of cells with different extracts are expressed for NR assay as percentages of the values obtained from cells incubated with the negative control and are the means $\pm \operatorname{SEM}(\mathrm{n}=4)(* *=\mathrm{p}<0.005)$.

They still presented intra-cytoplasmic granulation and vacuolization but were no longer confluent. This qualitative evaluation demonstrated no change of cellular morphology for cells exposed to bone and fascia lata allograft extracts (Fig. 1). However, we observed a decrease of confluence for Neuro 2A cells exposed to the fascia lata allograft extract at 48 and 72 hours.

\section{Quantitative evaluation}

The amount of formazan produced by WI38 exposed to the FF and FT extracts was not significantly altered (respectively $+4.76 \%, p=0.957$ and $+3.79 \%, p=0.609$ ) compared to this produced by cells incubated with the negative control. A decrease of this production was only significant for Neuro 2A exposed to the FT extract (- 28.54 $\%, p=0.036$ ) (Fig. 2). The Neutral Red incorporation in Neuro 2A exposed to the FT extract was significantly reduced by $42 \%(\mathrm{p}<0.005)$ compared to cells incubated with the negative control (Fig. 3). In addition, the membrane integrity of Neuro 2A exposed to the FT extract was decreased compared to the cells exposed to FF extract (- 53.7 $\%, \mathrm{p}<0.001)$.

The amount of formazan produced by WI38 exposed to the BT extract was decreased by $27.5 \%(\mathrm{p}<0.001)$ compared to that produced by cells incubated with the negative control (Fig. 4). This decrease was not confirmed in experiments with the specific cell line (SaOS-2) exposed to the BT extract $(-16.13 \%, p=0.259)$ (Fig. 4). In addition, no significant modification of succinate dehydrogenase activity was observed between cells (WI38 and SaOS-
2) exposed to the BF and BT extracts. The difference in Neutral Red incorporation in human fibroblasts and osteosarcoma cells between BT extract and non-toxic material was not significant $(+1.59 \%, \mathrm{p}=0.925$, and $-4.14 \%$, $\mathrm{p}=0.853$, respectively). A decrease of membrane integrity was observed for SaOS-2 exposed to the BF extract (- 31.4 $\%, \mathrm{p}<0.005$ ) (Fig. 5).

\section{Discussion}

The application of bone and fascia lata allografts which have been chemically processed is now the procedure of choice in order to minimize virus transmission. It is widely accepted that in vitro testing procedures are of considerable importance in allograft biocompatibility investigations. Although biocompatibility encompasses many properties of a material, in the present study the acute cytotoxic aspects of chemically inactivated allografts were investigated. The cell culture response upon exposure to human allografts extracts was estimated by qualitative and quantitative methods. The choice of the MTT and NR assays for quantitative evaluation was justified, based, respectively, on their sensitivity and reproducibility (Clifford and Downes, 1996). The MTT assay, which can estimate cell proliferation by the tetrazolium intracellular reduction, was by far the most sensitive assay of those investigated; although it was not as reproducible as some of the other tests (Borenfreund $e t$ al., 1988; Clifford and Downes, 1996; Dekker et al., 1994). 
The NR assay was considered as a less sensitive assay after 24 hours of cell incubation (Clifford and Downes, 1996). However, the NR uptake could be in-creased as the cells aged and lysosomes proliferated suggesting that this test could perform better if cultures were incubated for a period longer than 24 or 48 hours (Zhang et al., 1990). In the present study, the cell incubation time was 72 hours.

The observations in the present study allow us to draw two conclusions. First, the acute cytotoxicity evaluation of chemically treated allografts must be done with different cells involved in the tissue recolonization process. Second, results suggested that different methods must be combined to evaluate different aspects of acute cytotoxicity of the material. Quantitative methods did not show changes in homeostasis for fibroblastic cells incubated with chemically treated fascia lata extract. Enzyme activity and NR lysosomal incorporation in WI38 cells compared with cells exposed to the negative control extract did not change. Neuronal cells have shown a greater sensitivity to toxic substances released by the chemically treated fascia lata. Enzyme activity and membrane integrity of Neuro $2 \mathrm{~A}$ cells were modified following the exposition with this extract. This could be related to the decrease of Neuro 2A confluence at 48 and 72 hours after incubation with chemically treated fascia lata allograft. However, no change in cellular morphology was observed for WI38 and Neuro 2A cells exposed to this extract at 24, 48 and 72 hours. Standard and specific cell lines exposed to the bone extract also reacted differently. A significant decrease of intracellular dehydrogenase activity in fibroblasts exposed to the bone treated allograft was observed. However, this decrease was not confirmed with the osteosarcoma cells exposed to this extract. In addition, the membrane integrity was decreased when SaOS-2 cells were exposed to the fresh bone allograft.

This study demonstrates the importance of evaluating the impact of chemical treatment on different types of cells involved in the tissue recolonization process because these cells can have different sensitivity to the toxic substances released by the allograft. The methods used here offered the advantages of high sensitivity, speed, cost effectiveness and they allowed a qualitative, quantitative and a statistical approach (Clifford and Downes, 1996; Kirkpatrick and Mittermayer, 1990). However, in this study, we consider that the results from the MTT and NR assays must be analyzed separately because they evaluate two different metabolic functions: the reduction enzyme activity in the MTT assay and the membrane integrity in the NR assay.

The methods are based on the use of human and animal neoplastic or transformed cell lines because they demonstrate a good reproducibility and are very representative for the toxic effect on cells generated by allografts. However, we think that in the future the use of human primary cells at early passages could be applied in our model to investigate the impact of toxic release on cell phenotype such as inhibition of collagen synthesis by osteoblasts (Kirkpatrick and Mittermayer, 1990; Pariente et al., 1998). The present study showed that exposure of cultured cells to human allografts treated with a strong chemical treatment can be associated with a low acute cytotoxicity.

\section{References}

Borenfreund E, Babich H, Martin-Alguacil N (1988) Comparison of two in vitro cytotoxic assays - The neutral red (NR) and tetrazolium MTT tests. Toxicol in Vitro 2: 16.

Brown P, Gibbs CJ, Amyx HL, Kingsbury DT, Rohwer RG, Sulima MP, Gajdusek DC (1982) Chemical disinfection of Creutzfeldt-Jakob disease virus. N Engl J Med 306: 1279-1282.

Brown P, Rohwer RG, Gajdusek DC (1984) Sodium hydroxide decontamination of Creutzfeldt-Jakob disease virus. N Engl J Med 310: 727.

Buck BE, Malinin TI, Brown MD (1989) Bone transplantation and human immunodeficiency virus. An estimate of risk of acquired immunodeficiency syndrome (AIDS). Clin Orthop 240: 129-136.

Campbell DG, Oakeshott RD (1995) Bone allograft banking in South Australia. Aust N Z J Surg 65: 865-869.

Campbell DG, Peng Li, Stephenson AJ, Oakeshott RD (1994) Sterilization of HIV by gamma irradiation. International Orthopaedics 18: 172-176.

Clifford CJ, Downes S (1996) A comparative study of the use of colorimetric assays in the assessment of biocompatibility. J Mater Sci Mater Med 7: 637-643.

Conrad EU, Gretch DR, Obermeyer KR, Moogk MS, Sayers M, Wilson JJ (1995) Transmission of the hepatitis $\mathrm{C}$ virus by tissue transplantation. J Bone Joint Surg 77A: 214-224.

Conway B, Tomford W, Mankin HJ, Hirsch MS, Schooley RT (1991) Radiosensitivity of HIV-1. Potential application to sterilization of bone allografts. AIDS 5 : 608609.

Dekker A, Panfil C, Valdor M, Pennartz G, Richter H, Mittermayer Ch, Kirkpatrick CJ (1994) Quantitative methods for in vitro cytotoxicity testing of biomaterials. Cells Mater 4: 101-112.

Delloye C (1994) Tissue allografts and health risks. Acta Ortopaed Belgica 60: 62-67.

Dormont D (1996) Creutzfeldt-Jakob disease and transplantation: facts and fables. Transpl Proc 28: 2931-2933.

Eggen BM, Nordbo SA (1992) Transmission of HCV by organ transplantation. N Engl J Med 326: 412-413.

Fagès J, Marty A, Delga C, Condoret JS, Combes D, Frayssinet P (1994) Use of supercritical $\mathrm{CO}_{2}$ for bone delipidation. Biomaterials 15: 650-656.

Feinstone S, Mihalik K, Kanimura T (1983) Inactivation of hepatitis $\mathrm{B}$ virus and non-A, non-B hepatitis by chloroform. Infect Immun 41: 816-821.

Fideler BM, Vangsness T, Moore T, Li Z, Rasheed S (1994) Effects of gamma irradiation on the human immunodeficiency virus. A study in frozen human bone-patellar ligament-bone grafts obtained from infected cadavera. J Bone Joint Surg 76A: 1032-1035.

Forsell J (1993) Irradiation of musculoskeletal tissues. In: Musculoskeletal Tissue Banking. Tomford W (ed.). Raven Press. pp. 149-180.

Hernigou P, Marce D, Julieron A, Marinello G, Dormont D (1993) Sterilisation osseuse par irradiation et VIH. Rev Chir Orthop 79: 445-451. 
Johnson HJ, Northup SJ, Seagraves PA, Atallah M, Garvin PJ, Lin L, Darby TD (1985) Biocompatibility test procedures for materials evaluation in vitro. II. Objective methods of toxicity assessment. J Biomed Mater Res 19: 489-508.

Kearney J, Bojar R, Holland K (1993) Ethylene oxide sterilisation of allogenic bone implants. Clin Mater 12: 129135 .

Kirkpatrick CJ, Mittermayer C (1990). Theoretical and practical aspects of testing potential biomaterials in vitro. J Mater Sci Mater Med 1: 9-13.

Kirkpatrick CJ, Bittinger F, Wagner M, Köhler H, van Kooten TG, Klein CL, Otto M (1997a) Current trends in biocompatibility testing. Proc Instn Mech Engrs 212 Part H: 75-84.

Kirkpatrick CJ, Wagner M, Köhler H, Bittinger F, Otto M, Klein CL (1997b) The cell and molecular biological approach to biomaterial research: a perspective. J Mater Sci Mater Med 8: 131-141.

Lasarow RM, Rivkah Isseroff R, Gomez EC (1992). Quantitative in vitro assessment of phototoxicity by fibroblast - neutral red assay. J Invest Dermatol 98: 725729.

Lelie PN, Zaaijer HL, Cuypers HT (1996) Risk of virus transmission by tissue, blood and plasma products. Transplant Proc 28: 2939.

Loty B, Courpied J, Tomeno B, Postel M, Forest M, Abelanet R (1990) Radiation sterilized bone allografts. Int Orthop 14: 237-242.

Macnair R, Rodgers EH, Macdonald C, Wykman A, Goldie I, Grant MH (1997) The response of primary rat and human osteoblasts and an immortalized rat osteoblast cell line to orthopaedic materials: comparative sensitivity of several toxicity indices. J Mater Sci Mater Med 8: 105111.

Marshall NJ, Goodwin CJ, Holt SJ (1995) A critical assessment of the use of microculture tetrazolium assays to measure cell growth and function. Growth Regul 5: 6984.

Mosmann T (1983) Rapid colorimetric assay for cellular growth and survival: Application to proliferation and cytotoxicity assays. J Immunol Methods 65: 55-63.

Pariente JL, Bordenave L, Bareille R, Rouais F, Courtes C, Daude G, le Guillou M, Baquey C (1998) First use of cultured human urothelial cells for biocompatibility assessment: Application to urinary catheters. J Biomed Mater Res 40: 29-37.

Spire B, Barre-Sinoussi F, Montagnier L, Chermann JC (1984) Inactivation of lymphadenopathy associated virus by chemical desinfectants. Lancet 2: 899-901.

Spire B, Dormont D, Barré-Sinoussi F, Montagnier L, Chermann JC (1985) Inactivation of lymphadeno-pathyassociated virus by heat, gamma rays and ultraviolet light. Lancet 2: 188-189.

Srivastava S, Gorham SD, Courtney JM (1990) Screening of in vitro cytotoxicity by the adhesive film test. Biomaterials 11: 133-137.

Ulreich JB, Chvapil M (1981) A quantitative microassay for in vitro toxicity testing of biomaterials. $\mathrm{J}$ Biomed Mater Res 15: 913-922.

Verhulst C, Coiffard C, Coiffard LJM, Rivalland P, De
Roeck-Holtzhauer Y (1998) In vitro correlation between two colorimetric assays and the pyruvic acid consumption by fibroblasts cultured to determine the sodium laurylsulfate cytotxicity. J Pharmacol Toxicol Methods 39: 143-146.

World Health Organization (1992) Report of a WHO Consultation on Public Health Issues Related to Animal and Human Spongiform Encephalopathies. WHO/CDS/ VPH/92.104.

Zhang Q, Cornu O, Delloye C (1997) Ethylene oxide does not extinguish the osteoinductive capacity of demineralized bone. Acta Orthop Scand 68: 104-108.

Zhang SZ, Lipsky M, Trump B, Hsu IC (1990) Neutral red assay for cell viability and xenobiotic-induced cytotoxicity in primary cultures of human and rat hepatocytes. Cell Biol Toxicol 6: 219-234.

\section{Discussion with Reviewers}

J.A. Jansen: Will the authors also study mutagenic effects or do they consider this a non-relevant topic?

Authors: Other aspects of biocompatibility such as mutagenicity or cell adhesion, are actually studied but they are not the subject of this paper. This work was carried out to study the cytotoxicity of chemical treatment applied to the allograft to diminish the risk of virus, bacterial and prion transmission. We have chosen only the MTT and NR assays because those are very representative for cell viability. This work allowed to select an appropriate inactivation procedure with a low toxicity to cells involved in tissue recolonization. It is very important to consider the biocompatibility as a group of different tests which study the interaction between cell and biomaterial. Here, we have investigated the cytotoxicity, first stage of biocompatibility investigation.

J.A. Jansen: Do the authors suppose that another response will occur when primary cells are used?

Authors: With regard to the cytotoxicity aspect of biocompatibility, we are of the opinion that primary cells cannot show other responses compared with those observed with cell lines. We think that metabolic activity, studied in the cytotoxicity evaluation, cannot be significantly different between cell lines and primary cells. However, cell lines cannot be considered as primary cells for other aspects of biocompatibility because their phenotype is very different from that of primary cells.

M.H. Grant: Do the authors consider it useful to investigate cell-biomaterial interactions in dedifferen-tiated cell lines derived from cancer tissue?

Authors: We are of the opinion that cell lines are optimal to study the cytotoxicity parameters. Cell lines are very representative and reproducible for this aspect of biocompatibility. However, it is better to use primary cells to study other aspects of biocompatibility such as mutagenicity, cell adhesion or phenotype expression. In this case, we think that is more relevant to use primary osteoblastic cells, on the bone graft, to study e.g., collagen type I synthesis or osteocalcine expression. 